\title{
QUALITATIVE ANALYSIS OF FILTERS FOR THE MECHANICAL NANOFILTRATION OF HOUSEHOLD DRINKING WATER
}

\author{
OANA-ADRIANA CRISSAN ${ }^{a^{*}}$, MARIUS SORIN PUSTAN ${ }^{b}$, \\ CORINA JULIETA BÎRLEANỦ ${ }^{b}$, ANCUȚA ELENA TIUC ${ }^{a}$, IOANA SUR ${ }^{a}$, \\ HOREA-GEORGE CRISAN ${ }^{b}$, FLORINA MARIA ȘERDEAN ${ }^{b}$, \\ LAZĂR FLẢMÎND ${ }^{a}$, TIBERIU RUSU ${ }^{a}$
}

\begin{abstract}
The research carried out in this paper aimed to identify and compare the mechanical filtration capacity of the existing nanoparticles, correlated with the electro-chemical properties of the drinking water provided to the household users through the public network of Cluj-Napoca. The tested filters are available to the general public and the results of the research provide both the certainty of the importance of using drinking water filters, but also the prospect of purchasing an optimal relation quality - price filter based on the needs of the domestic users.

The qualitative analysis of the tested filters was carried out by laboratory testing of a representative sample of drinking water filters that once reached the maximum lifetime, were cut and subjected to microscopic analysis using an Atomic force microscope (AFM). The microscopic analysis aimed to determine the filtration capacity by identifying the size and agglomeration density of the nanoparticles retained by mechanical filtration.
\end{abstract}

Keywords: mechanical nanofiltration, atomic force microscopy, nanoindentation, optical microscopy, water filters, drinking water

\section{INTRODUCTION}

The low presence of eco-innovation in drinking water distribution companies has led, among other things, to the low interest of citizens to consume drinking water from the public network, which has determined the attention of the population towards the use of drinking water packaged in polyethylene terephthalate (PET) bottles [1].

a Technical University of Cluj-Napoca, Faculty of Materials and Environmental Engineering, 103-105 Muncii Ave, Cluj-Napoca, Romania

b Technical University of Cluj-Napoca, Faculty of Machine Building, 103-105 Muncii Ave, ClujNapoca, Romania

*Corresponding author: crisanoanaadriana@yahoo.com 
Therefore, the importance and necessity of approaching this topic is the continuous decrease of the quality of drinking water as a finite resource, this putting pressure on the researchers to find new approaches to water production and consumption. This is a new type of study that allows us to analyse with the cantilever the agglomeration and maximum dimensions of the remaining particles after testing the water filters in the household regime.

The premise of the research is that 400 billion litres of bottled water are consumed annually. Moreover, for bottling it in PET bottles (polyethylene terephthalate), 30 million barrels of oil and 7 times more water are consumed each year for the production of a single bottle compared to the one that is bottled [2]. In 2012, the global consumption of bottled water was amounted to 288 billion litres and was projected to reach 391 billion litres by 2017. In 2015 , there was the highest per capita consumption of bottled water in the world, in the amount of approximately 244,159 litres [3]. Thus, it is observed that the excessive use of bottled water in PET packaging is encouraged rather than its economy. Starting from these aspects, one of the most viable solutions in this regard, is the use of some filtration systems for water provided from the public network, installed at the users' home (at the final point of distribution of drinking water) [4]. Therefore, a major step for the protection of water consumption, possibly in Romania for several years, is the purchase of filters for drinking water, intended for domestic use $[5,6]$.

From a scientific point of view, the research of the efficiency of the drinking water filters intended for the domestic users, wants to contribute to the implementation of methods to increase the quality of the drinking water, by using the filter elements with high efficiency, through the identification of the nanometric dimensions, which contribute to the pollution of it.

From the technological point of view, it is reflected the importance of the use of drinking water filters in the domestic regime in order to increase the quality of life of the household users, to the detriment of the use of bottled drinking water [7]. The main difficulty lies in the policy of marketing strategies that encourage the use of bottled water in PET packaging. It can be concluded that several aspects related to the quality of bottled water in PET packaging, in relation to the drinking water filtered in the domestic regime, remains a topical subject that requires studies, followed by scientific answers [8].

The aim of this article is to:

- Compare the performances of two water filters from different materials (ceramic and polypropylene);

- To identify the possibilities of mechanical filtration of the pollutant particles of nanometric order, in correlation with the electro-chemical parameters of the drinking water; 
- To find the optimum filter element from the point of view of the qualityprice ratio, which ensures superior properties of drinking water coming from the public network and used in the domestic regime, which leads to the abandonment of the purchase and use of bottled water in PET packaging.

These determinations were made for the drinking water that was initially analysed to correspond to the specific chemical parameters, nanofiltration representing a next but imperative step in increasing the quality of the drinking water and discouraging the consumption of bottled drinking water.

\section{RESULTS AND DISCUSSION}

The first step required before testing the filters for drinking water is to determine the pollution level of the drinking water tested by analysing chemical indicators, for the two test points of the studied water network. The electrochemical parameters of drinking water can decisively influence the quality of the drinking water, but also the structure and distribution of the polluting mechanical nanoparticles (for example the oxides from the oxidation of the metallic pipes of drinking water distribution). Thus, this first step in performing quality analyses of drinking water, consists in ensuring that the tested drinking water corresponds to the electro-chemical parameters with parameters provided in the legislative norms and thus, the premise from which the testing of the filters for the mechanical retention of nanoparticles starts, to be a correct one. A particularly important group in the chemical analysis of water is the pollution indicators, together with other parameters necessary to establish the quality and purity of drinking water. In order to reveal the quality of the drinking water from the two selected points Cluj-Napoca and Gilău, an analysis of the main determining parameters was used $[9,10]$ : turbidity, $\mathrm{pH}$, electrical conductivity, dissolved oxygen in water and temperature. The results of the analyses of the water samples taken from the Iris area (sample $1 \mathrm{a}$ ), respectively the Gilău village (sample $1 \mathrm{~b}$ ) are shown in Table 1.

Compared with the results of the water quality bulletin issued by the Someș Water Company S.A., the values for the two sampling points are not similar. From the Table 1, it can be concluded that the determinant parameters, for both water samples, are in accordance with the limits allowed by the special laws that regulate these aspects [11,12], as well as with the methods of analysis of the specific standards. Also, it is noted that in the case of the first sample, the water has a higher conductivity and turbidity, whereas in the case of sample 2 , we can talk about a $\mathrm{pH}$ and a dissolved oxygen concentration also higher than the first sample analysed. So the higher presence of oxygen dissolved in water in the case of sample 2 signifies it has an increased freshness, a fact that benefits the inhabitants of the Gilău village. 
O.-A. CRIȘAN, M. S. PUSTAN, C. J. BîRLEANU, A. E. TIUC, I. SUR, H.-G. CRIȘAN, F. M. ȘERDEAN, L. FLĂMîND, T. RUSU

Table 1. The value of the water sample analyses for the two sampling points

\begin{tabular}{|c|l|c|c|c|c|c|}
\hline $\begin{array}{c}\text { Crt. } \\
\text { no. }\end{array}$ & $\begin{array}{l}\text { Determined } \\
\text { parameters }\end{array}$ & UM & \multicolumn{2}{|c|}{ The value obtained } & Permitted & $\begin{array}{c}\text { Analysis } \\
\text { limit }\end{array}$ \\
\cline { 4 - 7 } & Sample 1 a & Sample 1 b \\
l. & Turbidity & $F T U$ & 1 & 0,78 & $\leq 5$ & $\begin{array}{c}\text { SR EN ISO } \\
7027 / 2001\end{array}$ \\
\hline 2. & $p H$ & $p H$ units & 7,01 & 7,25 & $6,5-9,5$ & $\begin{array}{c}\text { SR ISO } \\
10523 / 2012\end{array}$ \\
\hline 3. & $\begin{array}{l}\text { Electrical } \\
\text { conductivity }\end{array}$ & $\mu \mathrm{S} / \mathrm{cm}$ & 99,5 & 83,3 & $<2500$ & $\begin{array}{c}\mathrm{SR} \mathrm{EN} \\
27888 / 97\end{array}$ \\
\hline 4. & $\begin{array}{l}\text { Oxygen } \\
\text { dissolved in } \\
\text { water }\end{array}$ & Mbar & 170,2 & 224 & $\begin{array}{c}>6 \mathrm{mg} \\
\mathrm{O}_{2} / \mathrm{l}\end{array}$ & $\begin{array}{c}\text { SR EN ISO } \\
5814: 2013\end{array}$ \\
\hline 5. & Temperature & ${ }^{\circ} \mathrm{C}$ & 23,5 & 20 & - & - \\
\hline
\end{tabular}

* according to Law 458/2002 republished in 2011 and of the Law 311/2004.

After the first step, we wanted to investigate which is the best type of filter between ceramic and polypropylene one, so that people can buy it and discard the PET type water packaging. For this, using the AFM microscope, a comparative analysis of the two main types of filters was performed.

In this sense, with the help of the XEI Park System software, after the maximum life cycle use, a comparative analysis was made which consisted of: a) the topography of the filters, b) roughness analysis and c) the larger particles size retained by each one. These three analyses represent an effective indicator for those who want to buy the best home water filter.

Scanning of ceramic and polypropylene cartridge samples. The microscopic analyses have the role of determining the quality of the drinking water filtration (from the point of view of the topography, roughness, size and density of the impurities deposited in the structure of the filter elements tested experimentally) and these objectives were possible to be achieved with the help of the atomic force microscope (AFM) [13]. From the obtained results it can be said that the efficiency of the filters is directly proportional to the value of the number of microns held by each one, for the capacity of filtration [14]. The maximum allowable surface scanned for the topography of the ceramic sample is $40 \times 40 \mu \mathrm{m}$, and for the topography of the polypropylene sample, due to the reduced dispersion of the determined particles, it was sufficient to analyse a surface of only $16 \times 16 \mu \mathrm{m}$. From Figure $1 \mathrm{a}$ ) and b) results a high density of particle agglomeration, with approximate heights of $2000 \mathrm{~nm}$, in the case of samples from ceramic material, while Figure $1 \mathrm{c}$ ) and d) show a much lower particle density agglomeration, with average heights up to $1000 \mathrm{~nm}$, in the case of polypropylene samples, for both test points [15]. 


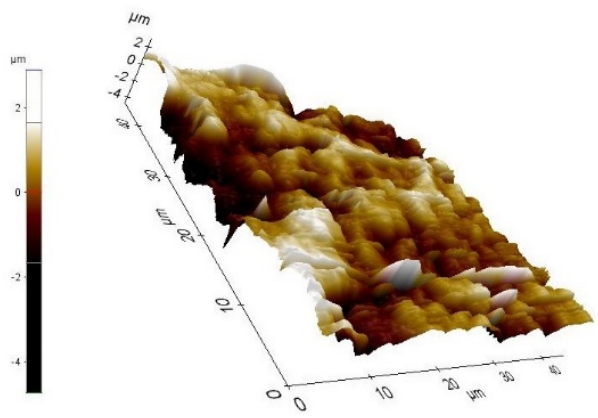

a)

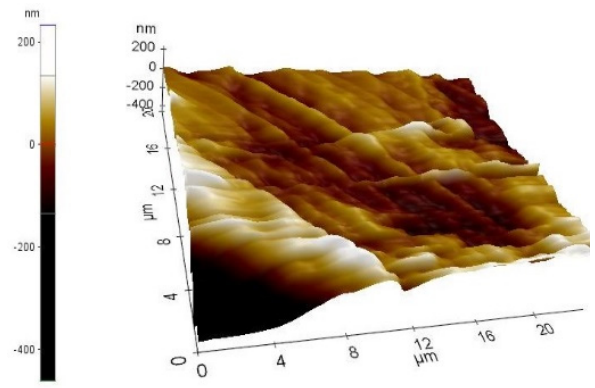

c)

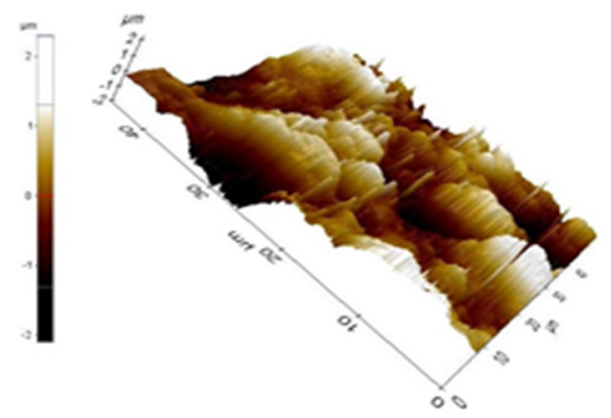

b)

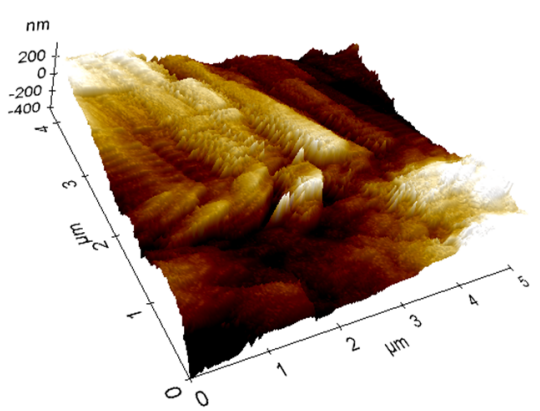

d)

Figure 1. Topography of the filter cartridge from: a) ceramic used in Cluj-Napoca; b) ceramic used in Gilău; c) polypropylene used in Cluj-Napoca; d) polypropylene used in Gilău

The surface scan of the samples of the analysed sample reflects several roughness parameters, but an important one is the average arithmetic height of the roughness which is called $R_{a}$. $R_{a}$ with high values shows the influence of the deposition of polluting particles in relation to the standard filtering surface [16] and also the quality of the filter.

Next, it was compared the most important roughness's recorded on the filter cartridges made of ceramic material, respectively polypropylene. In Figure $2 \mathrm{a}$ ), it was observed the surface roughness of the sample of ceramic material, where $R_{a}=984 \mathrm{~nm}$. In Figure $2 \mathrm{~b}$ ), also it was observed the roughness of the ceramic surface of the polypropylene filter element, where $\mathrm{R}_{\mathrm{a}}=62.239 \mathrm{~nm}$. 


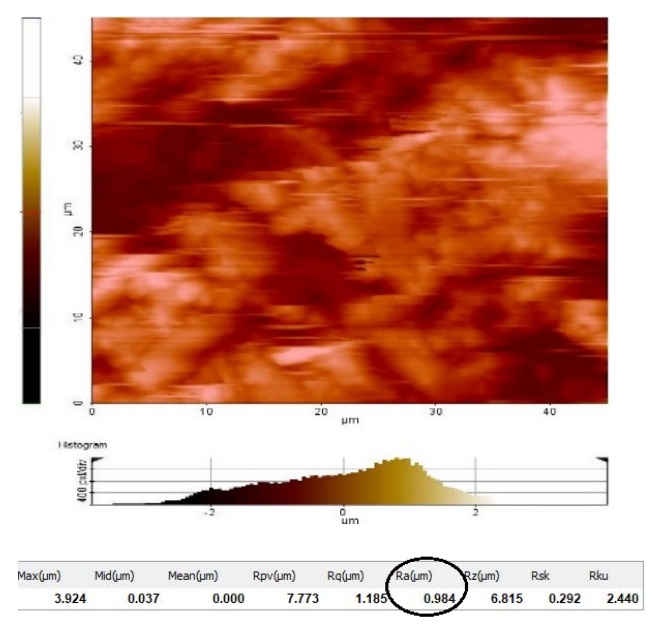

a)

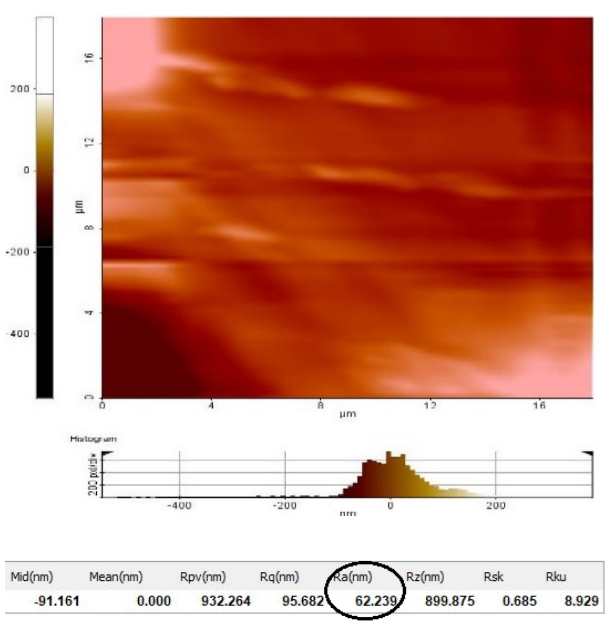

b)

Figure 2. The roughness of the cartridges from Cluj-Napoca:

a) ceramic type; b) polypropylene type

As can be seen from the value of the two roughness of the ceramic cartridges shown in Figure 2 a), respectively polypropylene from Figure 2 b), it can be stated that most deposits are registered on the first type of cartridge, with values of 15 times higher than the last one. On the opposite side, the low roughness of the surface of the polypropylene is reflected by the lower capacity of the filter tested, as can be seen from the particle density agglomeration, highlighted in the topography of Figure $1 \mathrm{c}$ ) and d). Due to the net superior roughness of the samples in the ceramic filter cartridge, it was made an individual analysis of the most relevant dimensional particles from analysed samples, deposited on the surfaces of the ceramic samples. For this, the samples taken from the Iris area and Gilău village were analysed. There are several relevant results regarding the efficiency of ceramic filters, so next there are several examples of depositions recorded on the sample probe analysed in Figures $3 \mathrm{a}$ ) and b) from the first test point, respectively on the sample probe from figures $4 a$ ) and b) from the second test point.

In the samples shown in Figure 3 a), a particle height dimension of $3969 \mathrm{~nm}$ is observed, while the next sample records a particle height dimension about to $2284 \mathrm{~nm}$. The sample from Figure 4 a) has a particle size of $2643 \mathrm{~nm}$, while the sample from Figure $4 \mathrm{~b}$ ) has a size of $2220 \mathrm{~nm}$. 


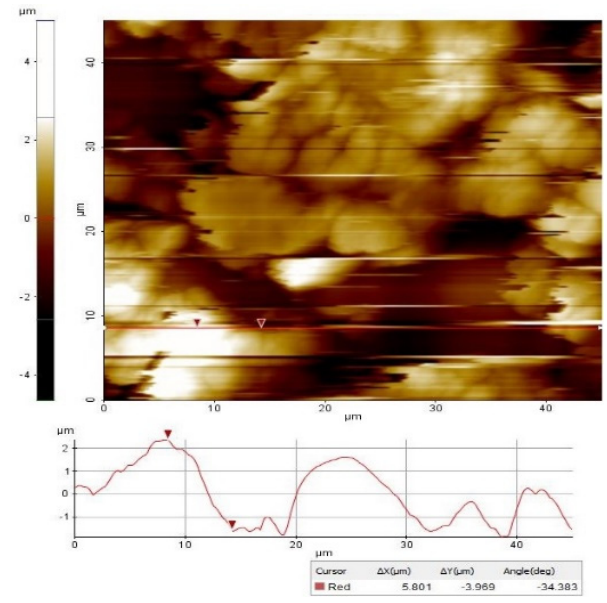

a)
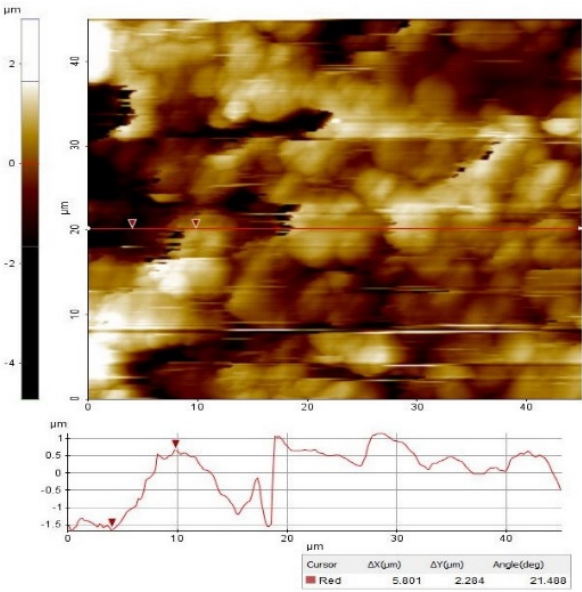

b)

Figure 3. The particle size of the ceramic cartridge from the first test point: a) sample 1 ; b) sample 2
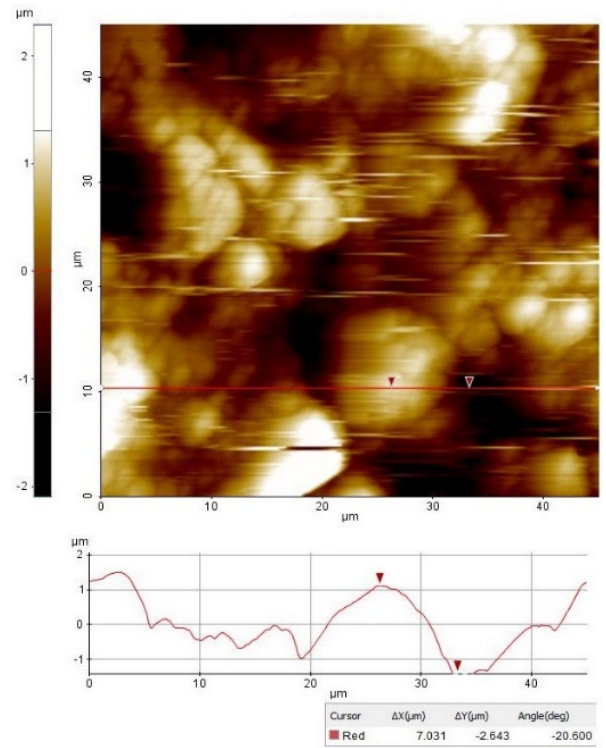

a)
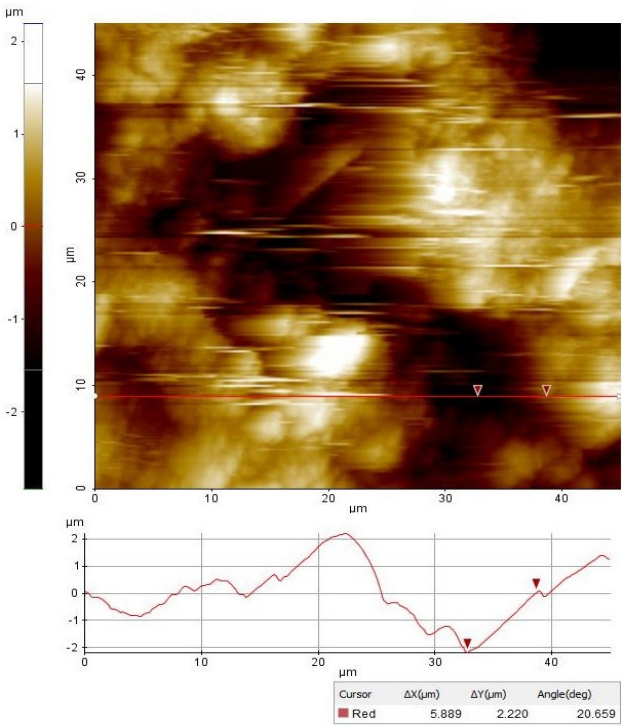

b)

Figure 4. The particle size of the ceramic cartridge from the second Test Point: a) sample 1 ; b) sample 2 
As a result of the tested samples, it can be observed that the largest deposits were registered on the ceramic cartridge from the first test point in Cluj-Napoca, which means that, in conjunction with the laboratory analyses performed for the two mentioned points, the water from the first tested area registered the most particle depositions. This aspect means that it is devoid of purity, which can cause various negative health effects for users. Considering the increased quality parameters of the water specified by the supplier, it can be seen that the increased level of polluting particles with significantly larger dimensions results from an unfavourable technical state of the water transport network from Cluj-Napoca Municipality.

Discussions. Corroborating the results of the topographic analyses with those of the roughness of the scanned surfaces, it is observed that the highest density of the particles retained by filtration is found on the ceramic sample. From the dimensional analysis of the relevant particles, it is found that, in the case of the ceramic sample, the structure of the material and its roughness allow the retention of a much larger number of particles, and the characteristics of the polypropylene material, although they allow the retention of a significant number of particles, their number is lower than the ceramic one. Thus, it is noted that the best filtering efficiency is held by the ceramic cartridge, which is one of the best indicators for both manufacturers and consumers who want to purchase a water filter with superior characteristics.

\section{CONCLUSIONS}

Although filters for domestic users have recently appeared on the domestic market, the benefits that it brings, compared to bottled water in PET containers, are much more financially, economic and social beneficial, with direct effects on the environment and population [16]. Providing a drinking water from the public network, with not only chemical parameters but also optimal mechanics, at a lower price than the one generated by the purchase and use of bottled drinking water, represents the objective achieved by the present study. This is one that supports the wise decision of consumers to use the optimum filter for drinking water from the network and thus to obtain drinking water of superior quality, while also avoiding the purchase and use of bottled drinking water in PET-type packaging - that are powerful pollutants on the environment.

\section{EXPERIMENTAL SECTION} following:

The steps followed for carrying out the experimental tests were the 
1) Taking water samples from two critical points of the water network; taken;

2) Analysis of the electrochemical parameters of the drinking water

3) Carrying out a classification of the filter elements according to their performance;

4) Performing experimental tests, using a sample of analyzed filters, on a specially developed experimental stand [15];

5) Collection of sections from the middle area of the tested filters (who reached the maximum life);

6) Identification of the filter with optimum nanofiltration capacities, in order to ensure the superior quality of the drinking water and from the perspective of mechanical impurities, not only chemical ones, which at the same time ensure an optimal quality-price ratio, with the purpose of its implementation among the domestic users, to the detriment use of bottled water in PET packaging.

Identification of the service areas that are subject of drinking water quality tests. In order to analyse the water samples quality, two diametrically opposed sampling points were chosen, both with the sole supplier, represented by the regional Water Somes Company. Being the water with superior electrochemical properties in the North-West region, an immediate next priority would be to improve its quality from the point of view of mechanical impurities (influenced by the distribution network) in order to be similar to bottled PET, but supplied drinking water at a much lower price. At the same time, a positive side effect is the reduction of the pollution degree of the environment, by the use of fewer and fewer PET-type packaging in which the drinking water is bottled.

Therefore, for the research, the first sampling point was located in the Iris district on the 103-105 Muncii Boulevard in the city of Cluj-Napoca, and the second being located in the village of Gilău, on Braniște street, number 172 in the area of Cluj. The reason for choosing the two areas was primarily that they are located at a considerable distance, more than $21 \mathrm{~km}$ from each other, which can lead to different effects of water quality, both before and after the installation of the filter elements.

Performing preliminary tests of drinking water. In order to carry out appropriate laboratory tests, using an experimental stand which can test the drinking water filters, it was necessary a primary determination of the quality characteristics, in terms of potability, of the water that will be the object of the experimental test. Thus, the following quality indicators were followed: turbidity, $\mathrm{pH}$, electrical conductivity, oxygen dissolved in water and temperature. With these parameters, it will be possible to determine the quality of the water coming from the SC WATER COMPANY SOMES S.A. treatment plant, from the two collection points, both before using the filters and after mounting them. Even if water from the underground source Florești is delivered into the municipality's 
network, this one, once reached at the pumping station in the Grigorescu district, it is mixed with the water coming from the Gilău Treatment Station, which came from Tarnița lake.

It is worth mentioning that what may differ substantially and may influence the characteristics of the water reached the household user, is the age of the interior water networks of the buildings or the technical state of the regional operator's distribution water network. For this reason, including the taste of water can be changed, which leads to the decision of people to consume packaged water in PET bottles. Therefore, through these analyses, it will be possible to determine precisely the water quality coming from the two diametrically opposed sampling points. Therefore, the quality of the water from the point of view of the electro-chemical parameters, can influence the formation of the type, size and structure of the polluting particles of mechanical order, thus there is a direct correlation between the two aspects (oxidized metallic particles, mineral deposits due to the age of the network, salt possible in agglomeration with other types of particles, etc.). The tested filters have the ability to retain these types of particles up to nanometric dimensions.

The first of the parameters - turbidity, is influenced by the presence in water of very fine suspensions that have the direct effect of water transparency. Its determination was made using the turbidimeter, in accordance with the standard SR EN ISO 7027/2001 [17]. The second determining parameter for the analysed water quality, is the $\mathrm{pH}$. A low $\mathrm{pH}$ below 7 indicates an acidic water, in which hydrogen ions are dominant. In contrast, a pH above 7 indicates a basic alkaline water, due to the dominant presence of oxydril ions. The $\mathrm{pH}$ determination was performed according to the standard SR EN ISO 10523/2012 [18], which establishes that this method applies to all samples of drinking or waste water, with a pH between 3 and 10 [19]. The third determining parameter for the research carried out, is the degree of electrical conductivity. The conductivity depends first of all by the presence of the salts dissolved in water and by its temperature. This analysis provides information with regard to the presence of salts in water. The instrument used for the measurement was the conductometer. The electrical conductivity of the water was determined according to the standard SR EN 27888/97 [20]. The fourth parameter analysed was the determination of the amount of oxygen dissolved in water. The presence of oxygen in water determines its quality. Absence of oxygen in water can have negative effects, such as, for example, changing the type of decomposing bacteria that lives in the aquatic environment, losing the freshness of the water or increasing the degree of pollution. The instrument used for this parameter was Multi 3430 . The presence of oxygen in the water was determined according to the standard SR EN ISO $5814 / 2013$ [21]. The last of the analysed parameters was the water temperature. Depending on its temperature, the maximum oxygen amount that can be dissolved in water, decreases with increasing of the temperature. The surface water temperature in Romania varies between 0 and $27^{\circ} \mathrm{C}$. 
Classifying the used water filter for microscopic analysis. For microscopic analysis, were tested two types of filters used for household water, which have superior filtration characteristics. Although these filter cartridges have superior filtering characteristics, guaranteed by the manufacturer, the purchase price is accessible to domestic users. For example, the average purchase price values of the 2 filter cartridges are equivalent to the purchase price of a shuttle bottle containing bottled water of 2 PET litre. Regarding the technicalfunctional characteristics of the filter cartridges, based on the manufacturer's declaration, the 2 filter cartridges tested have the following particularities:

a) Ceramic filter cartridge: used for mechanical filtration of rust particles, sand or other impurities, with dimensions up to $0.03 \mu$. Its durability is 3 months or maximum use in the amount of $3 \mathrm{~m}^{3}$. The maximum operating temperature is $30^{\circ} \mathrm{C}$.

b) Polypropylene filter cartridge: obtained by melting and expanding polypropylene, can retain mechanical impurities (sand, rust, etc.) up to $5 \mu$ in size. Its durability is 6 months or $3 \mathrm{~m}^{3}$ of water. The maximum operating temperature is $40^{\circ} \mathrm{C}$.

Analysis methods using microscopic infrastructure. The CAD environment [15] was used to design an experimental stand, which was constructed and used for the purpose of testing the chosen filters, under laboratory conditions. Also, for the analysis of the deposition results, the AFM technology was used, with which the 3D scan of the filter cartridge samples was performed. The samples are shown in figure 5 . The samples analysed from the representative sample were taken from the same middle area of the tested filters, as seen in figure $5 \mathrm{a}$ ) and $\mathrm{b}$ ), because the tests were performed on the experimental stand, having the uniform water flow and the thickness on the filter section was constant.

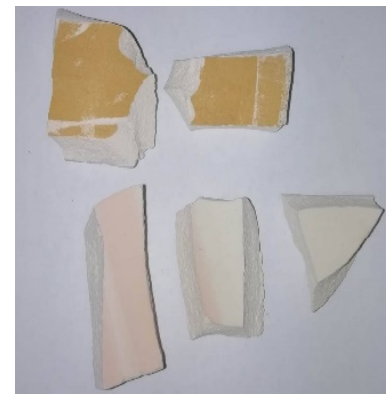

a)

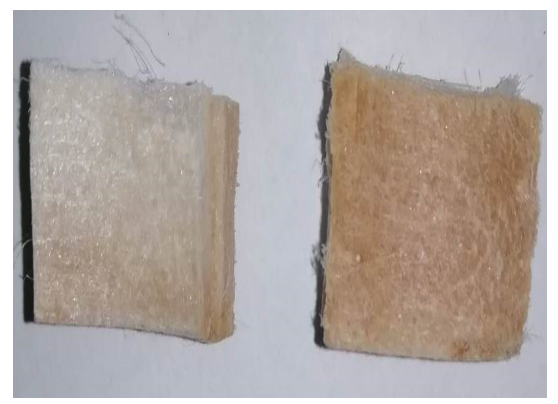

b)

Figure 5. Sectioned cartridge samples: a) ceramic; b) polypropylene 
At the end of the filter usage cycle, of $3 \mathrm{~m}^{3}$ of water, it was made a topographic analysis of the sample surfaces from the obtained samples and a mechanical nano characterization of the pollutant particle deposition from the Iris area and the Gilău village. Figure 6 shows the process of stand testing of one of the analysed filters.

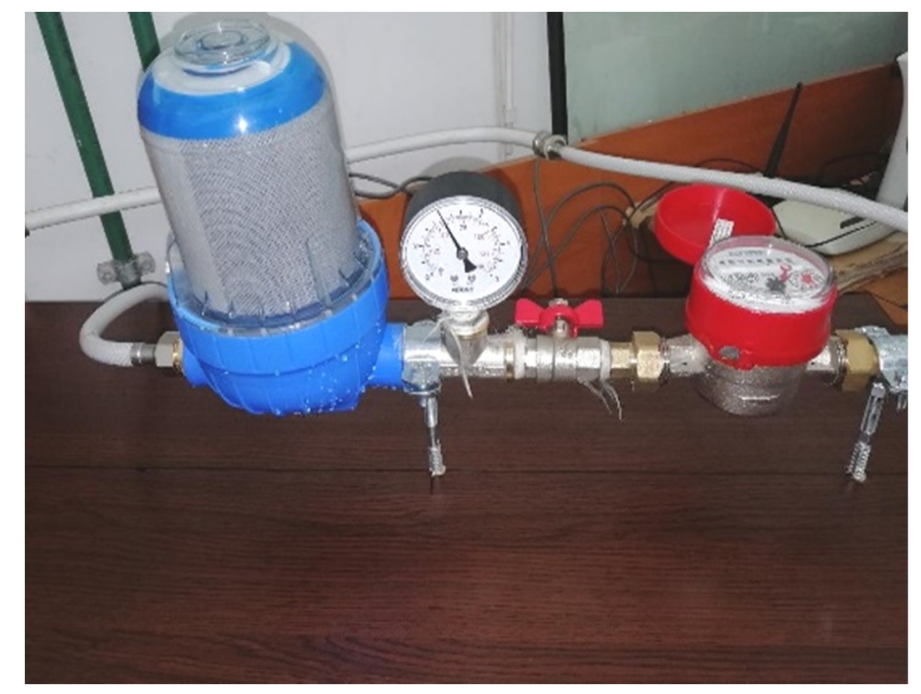

Figure 6. Filter testing on the experimental stand

Microscopic analysis. Also, for the analysis of the deposition results, the AFM technology was used, wherewith the 3D scanning of the tested samples was performed. This was made possible using the AFM XE 70 microscope from the MINAS research laboratory, from the Technical University of Cluj-Napoca, together with its software - XEI Park System. The tests were performed in non-contact mode, for a relative humidity of $28 \%$ at a room temperature of $23^{\circ} \mathrm{C}$. Topography determination and nano characterization were performed using a PPP-NCHR cantilever defined by: $4 \mu \mathrm{m}$ thickness, $30 \mu \mathrm{m}$ width, $125 \mu \mathrm{m}$ length, $400 \mathrm{kHz}$ resonance frequency and $42 \mathrm{Nm}^{-1}$ constant force; also the peak height is $15 \mu \mathrm{m}$ and the radius is less than $10 \mathrm{~nm}$ [22]. The roughness of the filter surfaces of the analysed samples is directly influenced by the size and distribution of the pollutant particles deposited, closely related to the structure of the material filter elements [23, 24].

\section{ACKNOWLEDGMENTS}

Special thanks goes to the MINAS Laboratory (Micro and Nano Systems Laboratory) research team, part of the Technical University of Cluj-Napoca. 


\section{REFERENCES}

1. J.-H Jo; T. Roh; S. Kim; Y.-C. Youn; M.S. Park; K.J. Han; E.K. Jang, J. Environ Sustain., 2015, 7, 16820-16835.

2. M. Arfanuzzaman, R. Atiq, Glob. Ecol. Conserv., 2017, 10, 9-22.

3. K. Webster, The Circular Economy: A Wealth of Flows - 2nd Edition; Ellen MacArthur Foundation Publishing, Cowes, UK, 2017, pp. 110-200.

4. S. G. Thornhill, M. Kumar, Life Sci. Space Res., 2018, 17,40-43.

5. E. Zanacic, J. Stavrinides, D. W. McMartin, J. Water Res., 2016, 104, 397-407.

6. Q. Xiaolei, P. J. J. Alvarez, L. Qilin, J. Water Res., 2013, 47, 3931-3946.

7. T. Wang, J. Kim, A. J. Whelton, Resour. Conserv. Recycl., 2019, 140, 115-124.

8. K. Pietrucha-Urbanik, B. Tchórzewska-Cieślak, Adv. Intel. Syst. Comput. 14th International Conference on Dependability of Computer Systems, DepCoSRELCOMEX, 2019, 987, 411-424.

9. S. Butaciu, M. Ponta, E. Darvasi, M. Frentiu, G. Horvath, T. Frentiu, Studia UBB Chemia., 2016, 3, 299-310.

10.E. Radu, R. Balaet, E. Vliegenthart, P. Schipper, Environm. Eng. Res., 2010, 15, 085-091.

11. ${ }^{* * *}$ Law no. $458 / 2002$ on the quality of drinking water, published in Romanian Official Monitor, part I, 875, 2011.

12. ${ }^{* * *}$ Law no. $311 / 2004$ on the quality of drinking water, published in Romanian Official Monitor, part I, 582, 2004.

13.W. G. Morris, Atomic Force Microscopy, in Encyclopedia of Materials: Science and Technology - second Edition; Pergamon, New York, USA, 2003, Volume 1, pp.1-6.

14.G. A. D. Briggs, B. J. Briscoe, Journal of Physics D: Applied Physics, 1959, Volume 10, No. 18, p. 2453.

15. H.G. Crișan, O. A. Crișan, M. S. Pustan, C. J. Bîrleanu, V.V. Merie, Microscopic testing and analysis of drinking water filters after the final life cycle, using an experimental stand, presented at The 14th International Conference on Tribology (ROTRIB'2019), Cluj-Napoca, 2019.

16. ${ }^{* * *}$ Directive (EU) 2019/904 of the European Parliament and of the Council of 5 June 2019 on reducing the impact of certain plastic products on the environment (Text with EEA relevance), published in Official Journal of the European Union, series L 155 of June 5, 2019.

17. *** SR EN ISO 7027/2001, standard for turbidity determination in water.

18. ${ }^{* * *}$ SR EN ISO 10523/2012, standard for measuring the $\mathrm{pH}$ value of water.

19. A. T. Rusu, Procedee și echipamente pentru tratarea și epurarea apelor Îndrumător de laborator, UT Press, Cluj-Napoca, Romania, 2013, pp.42-44; 4951.

20. ${ }^{* * *}$ SR EN 27888/97, standard for measuring the standard for measuring conductivity in water.

21. ${ }^{* * *}$ SR EN ISO 5814/2013, standard which establishes the electrochemical method for determining the dissolved oxygen content in water. 
O.-A. CRIȘAN, M. S. PUSTAN, C. J. BÎRLEANU, A. E. TIUC, I. SUR, H.-G. CRIȘAN,

F. M. SERDEAN, L. FLĂMÎND, T. RUSU

22.C. Bîrleanu, M. Pustan, V. V. Merie, H. G. Crișan, P. Romanian Acad. A, 2019, 20, 174-183.

23.V. Bellitto, Atomic Force Microscopy - imaging, measuring and manipulating surfaces at the atomic scale, published online: Intech, 2012.

24. L. Blunt, X. Jiang, Advanced techniques for assessment surface topography. Development of a basis for 3D surface texture standards "Surfstand", ButterworthHeinemann Publisher, 2003. 